\title{
APPLICATION OF COLOURED PETRI NETS IN THE PROSPECTIVE ANAL YSIS OF COOPERATIVE PROVISION OF INDUSTRIAL SERVICES
}

\author{
Katrin Winkelmann \\ Holger Luczak \\ Research Institute for Operations Management \\ at Aachen University of Technology \\ Pontdriesch 14/16, D-52062 Aachen, Germany \\ Telephone: +49 (0) 24147705230 \\ E-mail: \{Katrin.Winkelmann, Holger.Luczak\}@fir.rwth-aachen.de
}

\begin{abstract}
KEYWORDS
Coloured Petri nets, prospective analysis, industrial services, cooperation, performance analysis.
\end{abstract}

\begin{abstract}
Product-related services in the capital goods industry are characterised by international customer demands. Often these demands can only be met efficiently by cooperating with other partners. However, the decisionmaking process for cooperation configuration still lacks adequate support. Existing approaches for evaluating cooperation and services are not suitable for an assessment of different alternatives prior to their implementation. Simulation approaches for a cooperative provision of industrial services have not yet been developed. This paper deals with an approach to overcome this problem and presents a model based on Petri net theory for the prospective analysis of cooperative provision of industrial services. As a result, machine and equipment producers will be able to assess their cooperation alternatives related to integrated service provision in advance and thus avoid cost-intensive false decisions. To achieve this goal, a domain-specific conceptual model of cooperative provision of industrial services has been developed that considers the constitutive characteristics of industrial services and their cooperative provision and maps them onto the formal notation of Coloured Petri nets to form an executable simulation model.
\end{abstract}

\section{MOTIVATION}

Services are becoming increasingly important in the global economy and also in Germany's capital goods industry: German machine and equipment producers are realising an increasing percentage of their revenues with product-related services (Hoeck and Kutlina 2004). Product-related industrial services (e.g. repair or maintenance) are offered to (re)establish, ensure or enhance the long-term usability of industrial products. Since Germany's capital goods industry has an export rate of about 70 percent and its capital goods are sold around the globe, product-related services also have to be offered internationally (Bienzeisler and Meiren 2005; Wise and Baumgartner 1999). However, international provision of high-quality services requiring expert knowledge has proved to be cost-intensive and thus threatens the profit margin. Therefore, machine and equipment producers are looking for partners to form coalitions to improve their service business through cooperative advantages such as more efficient deployment of experts, shorter order processing times or cost reduction. In other words, the process of providing services for customers is no longer owned by one single company, but by several partners. This shared process is referred to as cooperative service provision.

While many companies have gained preliminary experience with cooperative service provision, the existence of problems in finding appropriate partners and reported organisational difficulties indicate that companies lack support for the planning and configuration of service networks (Zahn and Stanik 2003). A variety of alternatives related to cooperation and configurations complicates a substantiated decision (Winkelmann 2004). In this context, the possibility of assessing different cooperation alternatives before implementation, i.e. a prospective analysis, is needed.

To solve problems of this kind, a model for the prospective analysis of service network alternatives in the capital goods industry is needed (Luczak et al. 2005). This model has to consider the special requirements and characteristics of industrial services and their cooperative provision. In addition, it has to be represented in a formal notation that allows simulation and performance analysis.

The target is therefore to enable the prospective analysis of cooperative provision of industrial services. The chosen method of resolution is simulation with Coloured Petri nets (CPN). Coloured Petri nets are widely used to model business processes and workflows (Jensen 1997; van der Aalst 2002). The availability of many analytic techniques based on Petri nets is another advantage (Peterson 1981; Wang 1998; Girault and Valk 2003). Simulation is particularly suitable for assessing different alternatives before their actual implementation and has proven to be a successful method for prospective analysis of production network design (Banks 1998; Pritsker 1998; Zhou and Venkatesh 1999; Law and Kelton 2000). First applications of simulation in service have produced promising results (Laughery et al. 1998). 


\section{RELATION TO OTHER WORK AND NEED FOR ACTION}

First simulation applications for services were developed by Laughery et al. (1998) and Mjema (1997). Although these authors examined a prospective assessment for services, their approaches do not consider cooperation aspects. Petri net approaches in the workflow domain consider consumer-oriented services in particular (e.g. Jansen-Vullers and Reijers 2005; van der Aalst 2002), but they do not provide information about modelling cooperative provision of industrial services. Approaches in the field of evaluation of cooperation have proved to be of little value to the problem at hand, because of their focus on a retrospective analysis and management. Concepts based on the Balanced Scorecard (e.g. Merkle 1999; Bornheim and Stüllenberg 2002) benefit from the need to define assessment criteria, but remain superficial about operationalisation of these criteria.

With regard to controlling and quality management of industrial services, among others the approaches of Hlubek et al. (2004) and Luczak and Drews (2005) have proved useful. These authors have developed assessment criteria for industrial services at different levels of detail, and their results have been taken into account in the development of the simulation model presented in this paper.

The analysis of relevant literature shows that some approaches exist for parts of the problem, but shortcomings prevail, especially those related to the prospective analysis of alternatives of cooperative service provision. But existing approaches also do provide valuable information for solving different parts of the problem at hand: Simulation based on Petri nets as a method of prospective analysis has proven to be of great value, especially for complex cooperative processes. Coloured Petri nets in particular have proven to be a valuable modelling technique for complex cooperative processes and are applicable to cooperative service provision.

As a result of the deficits and advantages of existing approaches outlined above, the following tasks need to be addressed:

- A conceptual model for the cooperative provision of industrial services has to be developed.

- It has to be implemented into a simulation model based on Coloured Petri nets.

- The model has to be capable of prospective performance analysis of cooperative provision of industrial services.

\section{CONCEPTUAL MODEL OF COOPERATIVE PROVISION OF INDUSTRIAL SERVICES}

To create a model of cooperative provision of industrial services, the special characteristics of this domain have to be taken into account. These characteristics have to be integrated into a conceptual model of cooperative provision of industrial services before this model is translated into a CPN model.

\section{Requirements Resulting from Cooperative Provision of Industrial Services}

Services can be defined using constitutive attributes (Corsten 2001). This definition comprises three dimensions: process, structure, and outcome (Donabedian 1980).

The process dimension stresses the fact that the customer as the external factor has to be integrated into the process (Corsten 2001). Another important characteristic in the process dimension is the simultaneity of production and consumption of services in respect to time and space. Together with the integration of the external factor, this implies two specialities for industrial services that are not consumer-oriented but are rather business-to-business services in an industrial environment: Since services have to take place at the site of the product, required resources have to travel there. In addition, technicians of the client company often have to be integrated into the service process and work together with personnel of the service company. Services and especially industrial services are also very heterogeneous and standardisation of processes is not easy.

The structure dimension defines services as the ability to perform a service (Corsten 2001). This ability depends on the qualification of the available service personnel.

The simultaneity of process and production also affects the outcome dimension: It implies that there is no product whose quality can be measured in the end but the process itself is the service. Since services are not storable, this means that any delay in the process directly affects the quality of the services.

The conceptual model of cooperative provision of industrial services is based on these three dimensions and integrates the outlined characteristics of industrial services.

\section{Process dimension}

To represent the process of industrial service provision, a reference model has been developed (Kallenberg 2002). This reference model has been adapted to fit cooperative service provision and to fulfil the modelling requirements of the Petri net notation. Furthermore, the resulting model has been structured in a hierarchy: The top level provides a process overview; all process steps of this overview are then modelled in more detail (see Fig. 1). These sub-processes are can be interpreted as separate modules that interact via interfaces. This concept provides, on the one hand, flexibility, since modules can be changed easily and locally without having to deal with the whole model. On the other hand, it allows one to model process parts in sufficient detail while keeping complexity at the top level low.

To account for the heterogeneity of the process, different local process alternatives (e.g. necessity for problem description or revisions) have been defined. Probability functions control the flow of orders through these alternatives. 


\begin{tabular}{|c|c|}
\hline $\begin{array}{l}\text { Top level substitution } \\
\text { transitions }\end{array}$ & Transitions on detail level \\
\hline incoming requests & requests arrive \\
\hline receive request & $\begin{array}{l}\text { receive request } \\
\text { describe problem } \\
\text { analyse request }\end{array}$ \\
\hline clarify problem & $\begin{array}{l}\text { identify cause of problem } \\
\text { evaluate order } \\
\text { identify necessary serivce measures }\end{array}$ \\
\hline start order & record order \\
\hline plan order & $\begin{array}{l}\text { plan service measures } \\
\text { plan resources } \\
\text { plan costs } \\
\text { resources travel }\end{array}$ \\
\hline control order & $\begin{array}{l}\text { coordinate order } \\
\text { transfer order }\end{array}$ \\
\hline make changes & record change in order \\
\hline accomplish order & $\begin{array}{l}\text { check resource availability on-site } \\
\text { identify service object } \\
\text { execute order } \\
\text { check success } \\
\text { prepare revision } \\
\text { set process parameters } \\
\text { personnel travels back } \\
\text { restock service material }\end{array}$ \\
\hline confirm order & $\begin{array}{l}\text { describe order accomplishment } \\
\text { generate documentation } \\
\text { update database }\end{array}$ \\
\hline invoice order & $\begin{array}{l}\text { calculate service costs } \\
\text { invoice service order }\end{array}$ \\
\hline
\end{tabular}

Figure 1: Process Overview and Detail Level

\section{Structure dimension}

The structure dimension represents the resources needed to execute the processes. Mapped resources are different categories of personnel and material: service engineers, service technicians, client technicians for personnel and tools, spare parts, operating resources (like gaskets or lubricants) for material. Depending on the kind of order that has to be processed and its degree of difficulty, different categories and quantities of resources are needed and consumed.

The structure dimension also accounts for the mapping of different cooperation alternatives. The cooperation partners provide different resources and thus certain parameters change. Such parameters are the amount and structure of the provided resources and their consumption based on the degrees of difficulty of the orders. Depending on the location of the partners, times for personnel travel vary. The times required for fulfilling a service order and the probability of the need to correct this work depend on the qualification of personnel.

\section{Outcome dimension}

The outcome of a service is the finished service order which results from the process carried out by the resources. The outcome dimension of the model therefore comprises the set of all service orders and their status as they are fulfilled. This status contains different pieces of information: the degree of difficulty of the order, executed changes and revisions, and the order processing time. This information is used to calculate performance measures for the alternatives. Six performance measures have been defined in the three performance dimensions time, cost and quality (see Tab. 1). The conclusions based on the outcome of a comparison of cooperation alternatives may differ depending on the goals a company pursues in a cooperation.

Table 1: Performance Measures

\begin{tabular}{|c|c|c|c|}
\hline \multirow{2}{*}{$\begin{array}{c}\text { Perfor- } \\
\text { mance } \\
\text { measure }\end{array}$} & $\begin{array}{c}\text { Average time } \\
\text { in system }\end{array}$ & $\begin{array}{c}\text { Average } \\
\text { personnel } \\
\text { cost }\end{array}$ & First hit rate \\
\cline { 2 - 4 } & $\begin{array}{c}\text { Average } \\
\text { waiting time }\end{array}$ & $\begin{array}{c}\text { Personnel } \\
\text { utilisation }\end{array}$ & $\begin{array}{c}\text { Variance of } \\
\text { average time } \\
\text { in system }\end{array}$ \\
\hline
\end{tabular}

\section{IMPLEMENTATION OF THE MODEL BASED ON COLOURED PETRI NETS}

To transfer the conceptual model into a simulation model, the software CPN Tools of the University of Aarhus was used (CPN Tools). All aspects of the overall model were mapped into a directed graph consisting of places, transitions, arcs, and markings. In order to realise the hierarchical concept substitutions transitions and fusion places (duplicates of places which make the places accessible at different locations) were used. Since the detailed presentation of all model elements is beyond the scope of this paper, the implementation of some of the main concepts is presented below.

\section{Order Specific Model Definitions}

The primary markings in the net are orders that pass through the process. The colour set of orders (Order(i),j,k,l,l_d,m,n) is defined as follows:

colset Order $=$ product $\mathrm{A} * \mathrm{~B} * \mathrm{INT} * \mathrm{INT} * \mathrm{INT} * \mathrm{INT} * \mathrm{INT}$ timed;

colset $\mathrm{A}=$ index $\mathrm{A}$ with $0 . .3$;

colset $\mathrm{B}=$ with $\mathrm{N}|\mathrm{Ch}| \mathrm{Nr} \mid \mathrm{Chr}$; with $(\mathrm{N}=$ normal, $\mathrm{Ch}=$ change, $\mathrm{Nr}=$ normal revised, $\mathrm{Chr}=$ change revised).

Thus an order (Order(i),j,k,l,l_d,m,n) comprises an index (position i) to indicate its degree of difficulty and a status information (position $\mathrm{j}$ ) regarding changes and additions in the service assignment. The following integer values (positions k, l, l_d and $\mathrm{m}$ in $\operatorname{Order}(\mathrm{i}), \mathrm{j}, \mathrm{k}, \mathrm{l}, \mathrm{l} \_\mathrm{d}$, $\mathrm{m}, \mathrm{n}$ ) store different values that are needed to calculate performance measures. The last integer value (position $\mathrm{n}$ in $\operatorname{Order(i),j,k,l,1,d,m,n)}$ stores a one-to-one order number. This is an important requirement since, in order to model several concurrent processes, order copies with the same order number are created and have to be matched by comparing the order numbers when concurrent processes become synchronous. 


\section{Resource Specific Model Definitions}

Resource allocation is modelled with a separation between personnel and service material. Depending on the degree of difficulty of an order, different multi-sets of resources need to be allocated. A multi-set is a combination of several appearances of different colours, e.g. 1 service engineer +2 service technicians +3 client technicians. To be able to allocate resource multi-sets to an order, lists for personnel and material have been defined and added into a product colour set with the order.

\section{Process Specific Model Definitions}

The hierarchical concept described above was realised using the technique of substitution transitions. A substitution transition represents another page (subpage) in the net which starts and ends at the same places as the substitution transition, but contains a more detailed process comprising several other transitions and places. As depicted in Fig. 1, the process maps ten substitution transitions.

Local process alternatives are parallel procedures: An order runs through procedure A with a certain probability and through procedure B with another probability. To implement this concept, transitions that trigger local process alternatives create a random variable that is compared to probability values for the alternatives that have been configured in model initialisation (Winkelmann 2005). Fig. 2 gives an example of a sub-process with two local process alternatives.

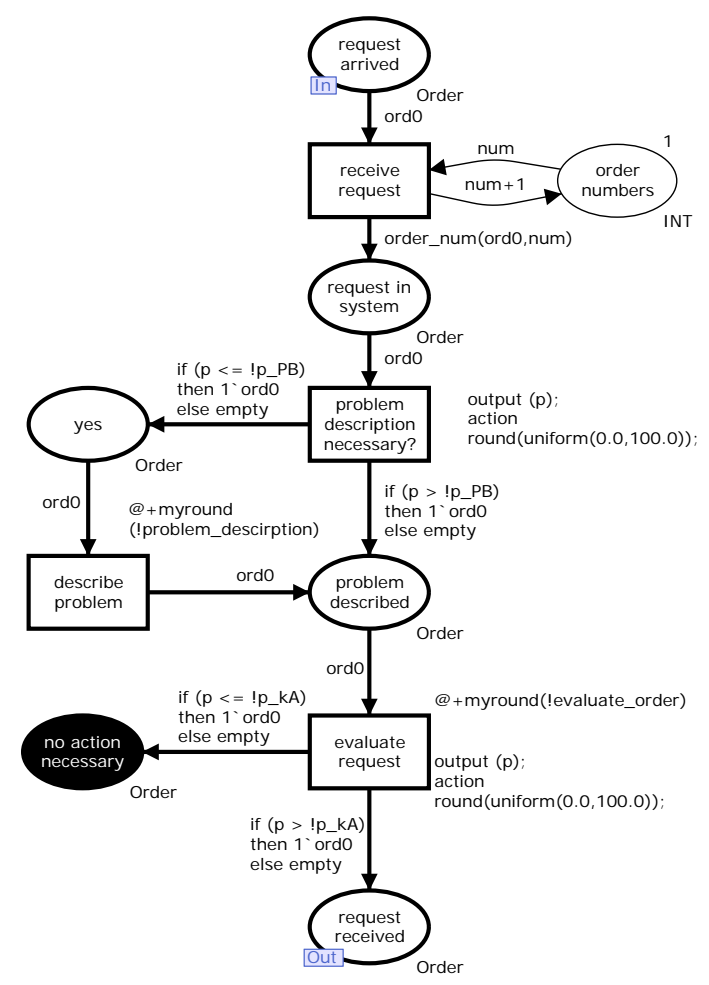

Figure 2: Sub-Process Receive Request with Local Process Alternatives

\section{Simulation Specific Model Definitions}

All time delays for process steps use random distribution functions, because the duration of the process steps varies. Since CPN Tools can handle time values only as integers, the real values of stochastic functions have been rounded, e.g. @+round(normal $(x, y))$. To be able to easily change the unit of the model time the function myround $(\mathrm{r})=$ round $(\mathrm{r} * \mathrm{~d})$ has been defined (JansenVullers and Reijers 2005). If the value of $d$ is set to 1.0, the unit of the model time is set to minutes.

To calculate and analyse simulation results, several monitors have been programmed in CPN Tools. They collect and process relevant data for the performance measures.

\section{Parameterisation}

To be able to initialise the model with user-specific starting and boundary conditions, these factors have been parameterised in the model by using global reference variables. That means that a company can specify the basic conditions of its service process by defining different values for the global reference variables. These parameters comprise time values for the different process steps and their stochastic functions (e.g. a Poisson arrival of requests) as well as probability values for certain process characteristics (e.g. the probability that an order has degree of difficulty of 2 or the probability that revisions are necessary).

To account for the concept of cooperative service provision, the model has to change with regard to different cooperation alternatives. This means that different parts of the process may be provided by different partners and thus may differ with respect of time, cost, and quality. Therefore additional parameters that are influenced by a change in responsibility of certain process steps have been added. The following cooperation-relevant parameters are used to configure cooperation alternatives for performance analysis: 1) probability of revision, 2) amount and structure of personnel, 3) personnel consumption per order, 4) cost of personnel 5) travel time of personnel, 6) time to accomplish order.

\section{EVALUATION}

The Coloured Petri net model implemented using CPN Tools has been evaluated concerning its correctness by verification, i.e. testing if the conceptual model has been implemented correctly (Desrochers and Al-Jaar 1995; Jensen 1997; Wang 1998; Cassandras and Lafortune 2001; Girault and Valk 2003). To do this, the full state space and strongly connected components graph were calculated and assessed concerning boundedness, liveness, fairness, and home markings. The results prove that all places are bounded with the upper and lower bounds as expected, deadlocks only exist for desired end states of the process and no infinite occurrence sequences exist.

Structural and behavioural validation is not a task to be performed at the end of model development, but rather 
accompanies the whole process of model development (Law and Kelton 2000). To validate the model, a panel of 14 subject matter experts was involved in the development of the model from the beginning. Several workshops and interviews with the experts have been organised. Joint development of the model, as well as a structured walkthrough of the conceptual model was used to validate the logic and assumptions of the model (Law and Kelton 2000; Robinson 2004). The use of common expressions in names of places and transitions, as well as the graphical representation and hierarchical structure of the model in CPN Tools have proven of high value to facilitate the communication with potential users and their understanding of the model. Interactive simulation was then used to assess the behaviour of the model (Law and Kelton 2000) and showed that the simulation results were consistent with perceived system behaviour.

An application of the performance analysis for three cooperation alternatives was carried out afterwards. The obtained results showed the effectiveness and plausibility of the comparison of alternatives using performance analysis based on simulation.

\section{Experimental Design}

In order to gain more information about the model and the effects of the cooperation parameters on the performance measures, an experimental design was carried out. In this case, a $2^{k}$ factorial design was used (Law and Kelton 2000; Robinson 2004). In this design all six cooperation parameters were varied systematically using two levels ( - and + ) for all factors, leading to $2^{6}=$ 64 design points. Main effects and two-factor interaction effects on two performance measures (average time in system and average personnel cost) and their 95\% confidence intervals were calculated using 64 replications in the design points with five simulations runs each (320 runs in total). The results were used to reproduce expected system behaviour, as depicted in Figures 3 and 4.

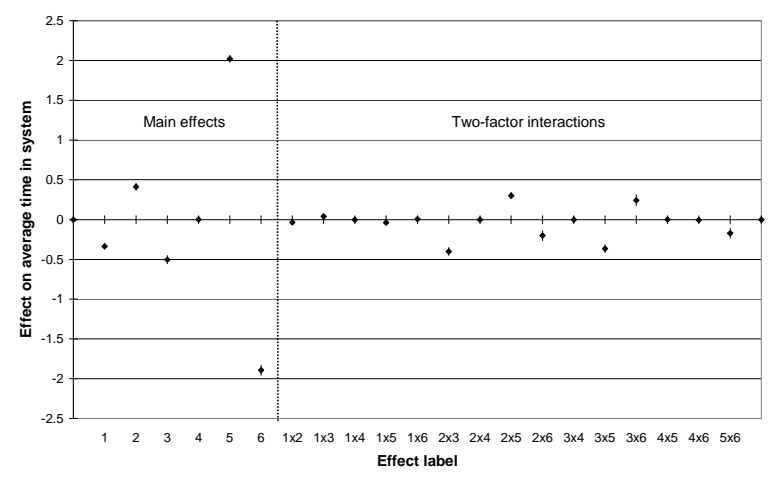

Figure 3: Effects on Average Time in System

Factors 5 and 6 (travel time and time to accomplish order) have the highest influence on the average time in system (see Fig. 3): Changing factor 5 from its - to its + level (i.e. a higher travel time) increases the time in system, while the same change in factor 6 (i.e. shorter time to accomplish order) decreases the time in system. Changes regarding available personnel, personnel cost, resource consumption, and the probability of revisions as well as two-factor interactions are less important compared to the effects of factors 5 and 6 .

A similar picture arises for the effects on the average personnel cost (see Fig. 4), with the difference that a change in factor 4 (cost of personnel) has the highest influence on the average personnel cost per order, as one would expect. In this case, the other main effects besides the ones of factors 4,5 , and 6 and the twofactor interactions are even less important.

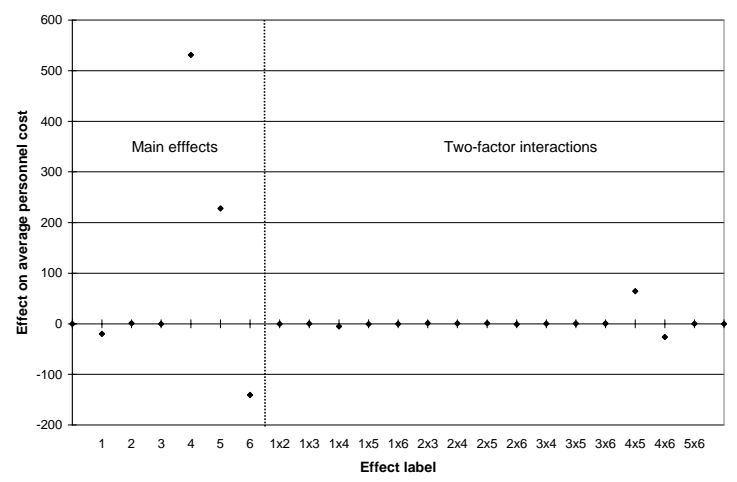

Figure 4: Effects on Average Personnel Cost

The results show that the model represents a consistent behaviour since no unreasonable effects were produced and the main influencing factors are feasible.

\section{CONCLUSIONS}

This paper presents a conceptual and simulation model of cooperative service provision in order to allow prospective analysis of cooperation alternatives. The model reflects the major features of industrial services as well as their cooperative provision. It allows prospective analysis of process organisation alternatives by varying factors relevant to cooperation and comparing analysis results.

The use of Coloured Petri nets as a modelling and simulation formalism provides several benefits: One the one hand, the graphical representation of the model leads to transparency, consistency, and conformity with user's expectations, so that understanding and acceptance of the model are facilitated. On the other hand, the maturity of the Petri net formalism and the availability of appropriate tools allow a direct implementation into computer models and their analysis.

Verification and validation of the model has shown that it properly maps the cooperative provision processes of industrial services and shows consistent behaviour. The influencing factors identified in a $2^{k}$ factorial design support these findings.

The $2^{k}$ factorial design will also be used in the future to investigate trade offs in regard to resource allocation or mechanisation, e.g. the deployment of different categories of personnel or the application of remote services. 
Future research should be directed in several interesting directions. Firstly, to facilitate communication with model users, the connection to animation and web based input/output facilities would be helpful. Secondly, investigations of fuzzy measues to integrate concepts which are not directly measurable, like trust between partners and cultural fit, would be very interesting. Finally, by applying simulation to industrial services, further integration of modelling and analysis of service provision and production of the corresponding investment goods has become more feasible. Future research should try to integrate simulation approaches of products and services to be able to better understand integrated product-service-systems. This should also lead to a more detailed collection of service process data. Here, industrial services have a backlog of demand, compared to production systems where simulation has already been established.

\section{ACKNOWLEDGEMENTS}

Part of this research is based on the project ServNET funded by the German Federal Ministry of Economics and Technology through the German Federation of Industrial Research Associations "Otto von Guericke" (Arbeitsgemeinschaft industrieller Forschungsvereinigungen "Otto von Guericke" e.V., FV-Nr. 14005 N).

\section{REFERENCES}

Banks, J. 1998. "Principles of Simulation." In Handbook of Simulation, Banks, J. (Eds.). Wiley, New York, 3-30.

Bienzeisler, B. and T. Meiren. 2005. Trendstudie Dienstleistungen. Fraunhofer- IAO, Stuttgart.

Bornheim, M. and F. Stüllenberg. 2002. "Effizienz- und Effektivitätssteuerung von Kooperationen mit Hilfe der Balanced Scorecard." Controlling 14, No.4/5, 283-289.

CPN Tools. http://wiki.daimi.au.dk/cpntools/ accessed $9^{\text {th }}$ January 2006.

Cassandras, C. G. and S. Lafortune. 2001. Introduction to Discrete Event Systems. Kluwer Acad. Publ., Boston.

Corsten, H. 2001. Dienstleistungsmanagement. Oldenbourg, Wien.

Desrochers, A. A. and R. Y. Al-Jaar. 1995. Applications of Petri Nets in Manufacturing Systems. IEEE Press, N.Y.

Donabedian, A. 1980. Explorations in Quality Assessment and Monitoring. Vol. 1. Health Admin. Press, Ann Arbor.

Girault, C. and R. Valk. 2003. Petri Nets for Systems Engineering. Springer, Tokyo.

Hlubek, W.; G. Pötzsch and J. Kesting. 2004. "Certified Service." In Betriebsorganisation im Unternehmen der $\mathrm{Zu}$ kunft, Luczak, H. and V. Stich (Eds.). Springer, Berlin, 167-187.

Hoeck, H. and Z. Kutlina. 2004. Status quo und Perspektiven im Service 2004. Verlag Klinkenberg, Aachen.

Jansen-Vullers, M. H. and H. A. Reijers. 2005. "Business Process Redesign at a Mental Healthcare Institute." In Sixth Workshop and Tutorial on Practical Use of Coloured Petri Nets and the CPN Tools: Aarhus, Denmark, October 24-26, 2005, Jensen, K. (Eds.). Computer Science Dept., Aarhus Univ., Aarhus, 21-38.

Jensen, K. 1997. Coloured Petri Nets. Springer, Berlin.

Kallenberg, R. 2002. Ein Referenzmodell für den Service in Unternehmen des Maschinenbaus. Shaker, Aachen.
Laughery, R.; B. Plott and S. Scott-Nash. 1998. "Simulation of Service Systems." In Handbook of Simulation, Banks, J. (Eds.). Wiley, New York, 629-644.

Law, A. M. and W. D. Kelton. 2000. Simulation Modeling and Analysis. McGraw-Hill, Boston.

Luczak, H. and P. Drews (Eds.). 2005. Praxishandbuch Service-Benchmarking. Service Verlag Fischer, Landsberg.

Luczak, H.; K. Winkelmann and H. Hoeck. 2005. "Internationalisierung von industriellen Dienstleistungen." In Internationalisierung von Dienstleistungen, Bruhn, M. and B. Stauss (Eds.). Gabler, Wiesbaden, 389-413.

Merkle, M. 1999. Bewertung von Unternehmensnetzwerken. St. Gallen.

Mjema, E. 1997. A Simulation Based Method for Determination of Personnel Capacity Requirement in the Maintenance Department. Shaker, Aachen.

Peterson, J. L. 1981. Petri Net Theory and the Modeling of Systems. Prentice-Hall, Englewood Cliffs.

Pritsker, A. A. B. 1998. "Principles of Simulation Modeling." In Handbook of Simulation, Banks, J. (Eds.). Wiley, New York, 31-51.

Robinson, S. 2004. Simulation. Wiley, Chichester.

van der Aalst, W. M. P. 2002. "Putting Petri Nets to Work in the Workflow Arena." In Petri Net Approaches for Modelling and Validation, van der Aalst, W. M. P.; J. - M. Colom; F. Kordon; G. Kostis and D. Moldt (Eds.). LINCOM Europa, München, 125-143.

Wang, J. 1998. Timed Petri Nets. Kluwer Acad. Publ., Boston.

Winkelmann, K. 2004. "Werkzeug zur Entscheidungsunterstützung von KMU bei der Planung von Netzwerken zur Erbringung industrieller Dienstleistungen." In Virtuelle Organisation und neue Medien 2004: Workshop GeNeMe 2004, TU Dresden, 7. und 8. Oktober 2004, Engelien, M. and K. Meißner (Eds.). Eul, Lohmar , 407-418.

Winkelmann, K. 2005. "Application of Coloured Petri Nets in Cooperative Provision of Industrial Services." In Sixth Workshop and Tutorial on Practical Use of Coloured Petri Nets and the CPN Tools: Aarhus, Denmark, October 2426, 2005, Jensen, K. (Eds.). Computer Science Dept., Aarhus Univ., Aarhus, 285-300.

Wise, R. and R. Baumgartner. 1999. "Go Downstream" Harvard Business Review 77, No.5, 133-144.

Zahn, E. and M. Stanik. 2003. "Wie Dienstleister gemeinsam den Erfolg suchen." In Dienstleistungsnetzwerke, Bruhn, M. and B. Stauss (Eds.). Gabler, Wiesbaden, 593-612.

Zhou, M. and K. Venkatesh. 1999. Modeling, Simulation and Control of Flexible Manufacturing Systems. World Scientific, Singapore.

\section{AUTHOR BIOGRAPHIES}

HOLGER LUCZAK is Emeritus of the Chair and Institute of Industrial Engineering and Ergonomics as well as the Research Institute for Operations Management at Aachen University of Technology. He is president of the Association of Ergonomics (Gesellschaft für Arbeitswissenschaft, GfA). His e-mail address is: Holger.Luczak@fir.rwth-aachen.de.

KATRIN WINKELMANN is scientific assistant at the Research Institute for Operations Management at Aachen University of Technology. She is coordinator of the service engineering research group in the department of service management. Her e-mail address is: Katrin.Winkelmann@fir.rwth-aachen.de. 